\title{
Fungal Metabolite Ophiobolin A as a Promising Anti-Glioma Agent: In Vivo Evaluation, Structure-Activity Relationship and Unique Pyrrolylation of Primary Amines
}

\author{
Ramesh Dasari, ${ }^{a}$ Marco Masi, ${ }^{b}$ Romana Lisy, ${ }^{\mathrm{c}}$ Marlène Ferdérin, ${ }^{\mathrm{c}}$ Lance R. English, ${ }^{\mathrm{a}}$ \\ Alessio Cimino, ${ }^{\mathrm{b}}$ Véronique Mathieu, ${ }^{\mathrm{c}}$ Andrew J. Brenner, ${ }^{\mathrm{d}}$ John G. Kuhn, ${ }^{\mathrm{d}}$ Steven T. \\ Whitten, ${ }^{a}$ Antonio Evidente, ${ }^{b}$ Robert Kiss, ${ }^{c}$ and Alexander Kornienko ${ }^{\mathrm{a},}{ }^{*}$ \\ ${ }^{a}$ Department of Chemistry and Biochemistry, Texas State University, San Marcos, Texas 78666, USA \\ ${ }^{b}$ Dipartimento di Scienze Chimiche, Università di Napoli Federico II, Complesso Universitario \\ Monte Sant'Angelo, Via Cintia 4, 80126 Napoli, Italy \\ ${ }^{c}$ Laboratoire de Cancérologie et de Toxicologie Expérimentale, Faculté de Pharmacie, Université \\ Libre de Bruxelles, Brussels, Belgium \\ ${ }^{d}$ Cancer Therapy and Research Center, The University of Texas Health Science Center at San \\ Antonio, 7703 Floyd Curl Drive, San Antonio, Texas 78229, USA
}

\section{Graphical Abstract}
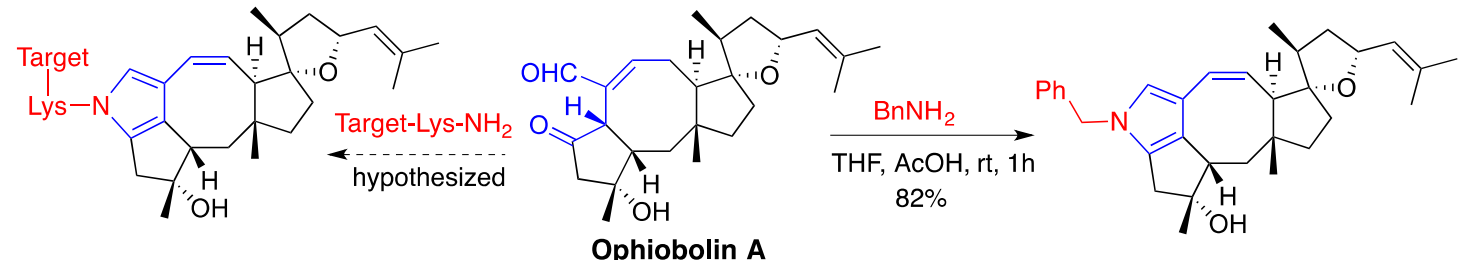

\begin{abstract}
Glioblastoma, the most common form of malignant primary brain tumor, is characterized by resistance to apoptosis, which is largely responsible for the low effectiveness of the classical chemotherapeutic approaches based on apoptosis induction in cancer cells. Previously, a fungal secondary metabolite ophiobolin A was found to have significant activity against apoptosisresistant glioblastoma cells through the induction of a non-apoptotic cell death, thus, offering an innovative strategy to combat this type of cancer. The current work describes the results of a preliminary evaluation of ophiobolin $\mathrm{A}$ in an in vivo glioblastoma model and its chemical derivatization to establish first synthetically generated structure-activity relationship. The synthetic work has also led to the discovery of a unique reaction of ophiobolin A with primary amines suggesting the possibility of pyrrolylation of lysine residues on its intracellular target protein(s).
\end{abstract}

Keywords: Paal-Knorr; pyrrole; paraptosis; 1,4-dicarbonyl.

* Corresponding author. Tel: +1 512245 3632; Fax: +1 512245 2374; Email: a_k76@txstate.edu (A. Kornienko) 
Glioblastoma (GBM) is one of the top ten causes of cancer-related deaths. ${ }^{1}$ The standard treatment for GBM patients includes surgery followed by radiotherapy with concomitant chemotherapy with temozolomide. ${ }^{2,3}$ Nevertheless, the prognosis is poor and the median survival is only 14.6 months. ${ }^{3}$ About half of GBM patients harbor an unmethylated MGMT promoter and they respond poorly to temozolomide chemotherapy. ${ }^{4,5}$ To date, no alternative treatment exists for this group of patients. The development of molecularly targeted therapy has been a focus of current GBM research and recently more than 50 such targeted agents entered clinical trials. ${ }^{6}$ To date, however, these have failed to improve clinical outcomes. ${ }^{6-8}$ Despite a significant pace of drug discovery research, the median survival of GBM patients has not changed over the past 10 years and the GBM clinic is in dire need of conceptually new treatment strategies.

GBM cells are generally highly resistant to the classical pro-apoptotic therapeutic approaches. ${ }^{9}$ Although a great deal of research has been aimed at rendering cancer cells more susceptible to therapy-induced apoptosis, ${ }^{10}$ over the past decade a growing number of non-apoptotic cell death pathways have been revealed and compounds that induce anoikis, autophagy, regulated necrosis, mitotic catastrophe, paraptosis, parthanatos, methuosis, and lysosomal membrane permeabilization, are being investigated in clinical trials, with several agents already approved for the treatment of various cancers. ${ }^{11}$ Our labs have been pursuing the identification of new anti-GBM agents working through alternative non-apoptotic mechanisms, ${ }^{12-20}$ and in the first demonstration of a specific induction of paraptosis in GBM cells with a small molecule, we discovered that ophiobolin A (Figure 1), a fungal metabolite from Bipolaris species, exhibited promising activity against apoptosisresistant GBM cells through the induction of paraptosis. ${ }^{12}$ Paraptosis is a form of non-apoptotic cell death characterized by a process of vacuolization that begins with the physical enlargement of mitochondria and the endoplasmic reticulum (ER). ${ }^{21,22}$ It is accompanied by the absence of apoptotic morphology, DNA fragmentation, caspase activation or poly(ADP-ribose) polymerase (PARP) cleavage. ${ }^{21,22}$ Although this cell death is prevented by inhibitors of protein synthesis and transcription, indicating that it is programmatic in nature, apoptosis inhibitors are ineffective in preventing paraptosis, identifying it as a distinct biochemical process. Moreover, paraptosis was found to be a relevant cell death process in the brain tissue of GBM patients. ${ }^{23}$

Ophiobolin A was evaluated in the NCI panel of 60 cell lines, where it registered an average $\mathrm{GI}_{50}$ value of $70 \mathrm{nM}$. Correlations of the differential cellular sensitivities reveal a possibly novel mechanism of action compared with $>763 \mathrm{~K}$ compounds in the NCI database. Furthermore, nonproliferating keratinocytes displayed 5-10X lower sensitivity to ophiobolin A than cancer cells and this agent was shown not to be a substrate for MDR-related efflux pumps. ${ }^{24}$ Ophiobolin $\mathrm{A}$ is a member of a large family of over 25 natural ophiobolins that have been isolated from various species of phytopathogenic fungi. ${ }^{25}$ A number of them have been evaluated for cytotoxicity against cancer cells, providing the initial structure-activity relationship (SAR) data. These data identify the C5,C21dicarbonyl functionality as critical for anticancer activity in this family of natural products. Indeed, changes that may affect the reactivity of this functionality, such as those represented by 6-epi- and anhydro-ophiobolin A (Figure 1), result in a significant drop in activity. ${ }^{26}$ Moreover, the elimination of one of these carbonyl groups from the molecule, such as that in 21,21-O-dihydroophiobolin A, leads to a complete loss of activity. ${ }^{26}$ In contrast, changes in the $\mathrm{C} 15-\mathrm{C} 25$ fragment, such as that found in ophiobolin $\mathrm{K}$, are tolerated. ${ }^{27,28}$ 


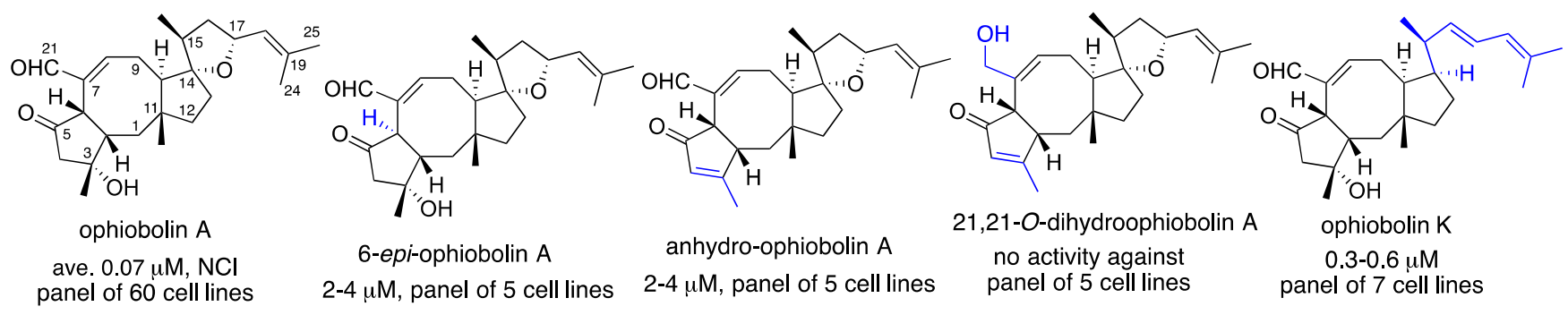

Figure 1. SAR of natural ophiobolin A congeners

Despite its promise in the treatment of GBM, ophiobolin A has not been evaluated in an in vivo GBM model and its ability to cross the blood-brain barrier (BBB) has not been tested. Furthermore, no synthetic studies aimed at ophiobolin A derivatization have been reported to our knowledge and, thus, no synthetically generated SAR are available. Finally, the specific types of reactions that the reactive $\mathrm{C} 5, \mathrm{C} 21$-dicarbonyl functionality can undergo and that could be important in the biological environment have not been reported. The present investigation fills these gaps in the literature and describes a study aimed to address the above questions. ${ }^{29}$

A pilot in vivo experiment in an orthotopic mouse GBM model was performed (IP, $10 \mathrm{mg} / \mathrm{kg}$ ophiobolin A), 3x per week for a total of 21 days) revealing both statistically significant survival of mice bearing orthotopic U251-LUC tumors (Figure 1, left) and tumor growth reduction (Figure 1, right). Although conducted in a pilot manner without the optimization of the administration route, dose or treatment regimen, the initial positive results bode well for the successful development of ophiobolin A-based analogs or prodrugs with efficacious in vivo activity in GBM. Additionally, the ability of ophiobolin A to cross the blood-brain barrier (BBB) was demonstrated by injecting this metabolite intravenously into the lateral tail vein of a tumor bearing mouse and detecting it in an intact form 15 minutes post administration in the brain tumor extract (data not shown).
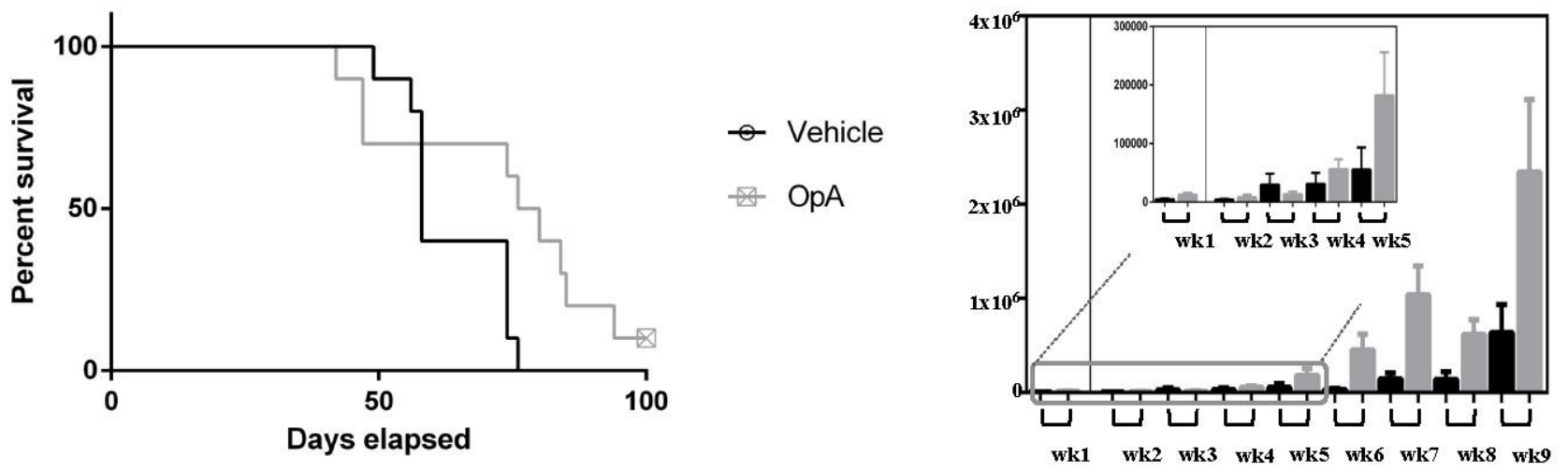

Figure 2. (Left) Survival of ophioblin A-treated mice bearing orthotopic U251-LUC tumors. Mice inoculated with $1 \times 10^{6}$ U251-LUC cells were treated with $10 \mathrm{mg} / \mathrm{kg}$ ophiobolin A 3x per wk for a total of 21 days. Mice with no signs of GBM were sacrificed on day 100 after inoculation and were considered long term survivors. (Right) Temporal imaging of tumor growth after innoculation with U251luciferase-expressing human GBM tumor cells. Relative growth in response to $10 \mathrm{mg} / \mathrm{kg}$ ophiobolin A (black columns) or $0.9 \%$ saline vehicle control (grey columns).

Synthetic derivatization of ophiobolin A began with the study of the reactivity of the C5,C21dicarbonyl functionality (Figure 3). It was found that in the presence of acid, ophiobolin A reacted with alcohols to form bis-acetals 1-3. Acetals $\mathbf{1}$ and $\mathbf{2}$ were isolated as single diastereomers at $\mathrm{C} 5$ and $\mathrm{C} 21$, whereas 3 consisted of a mixture of C21-epimers. In addition, ophibolin A readily formed 
aromatic rings, such as pyridazine $\mathbf{4}$ and furan $\mathbf{5}$ upon reactions with hydrazine and acetic anhydride, respectively. Furthermore, the $\mathrm{C} 21$-aldehyde was converted into $\alpha, \beta$-unsaturated esters $\mathbf{6}$ and 7, and nitrile 8, when treated with stabilized Wittig reagents. Lastly, dehydration with the formation of $\mathrm{C} 3, \mathrm{C} 4$-alkene 9 was observed when the natural product was treated with acid in the absence of alcohols.

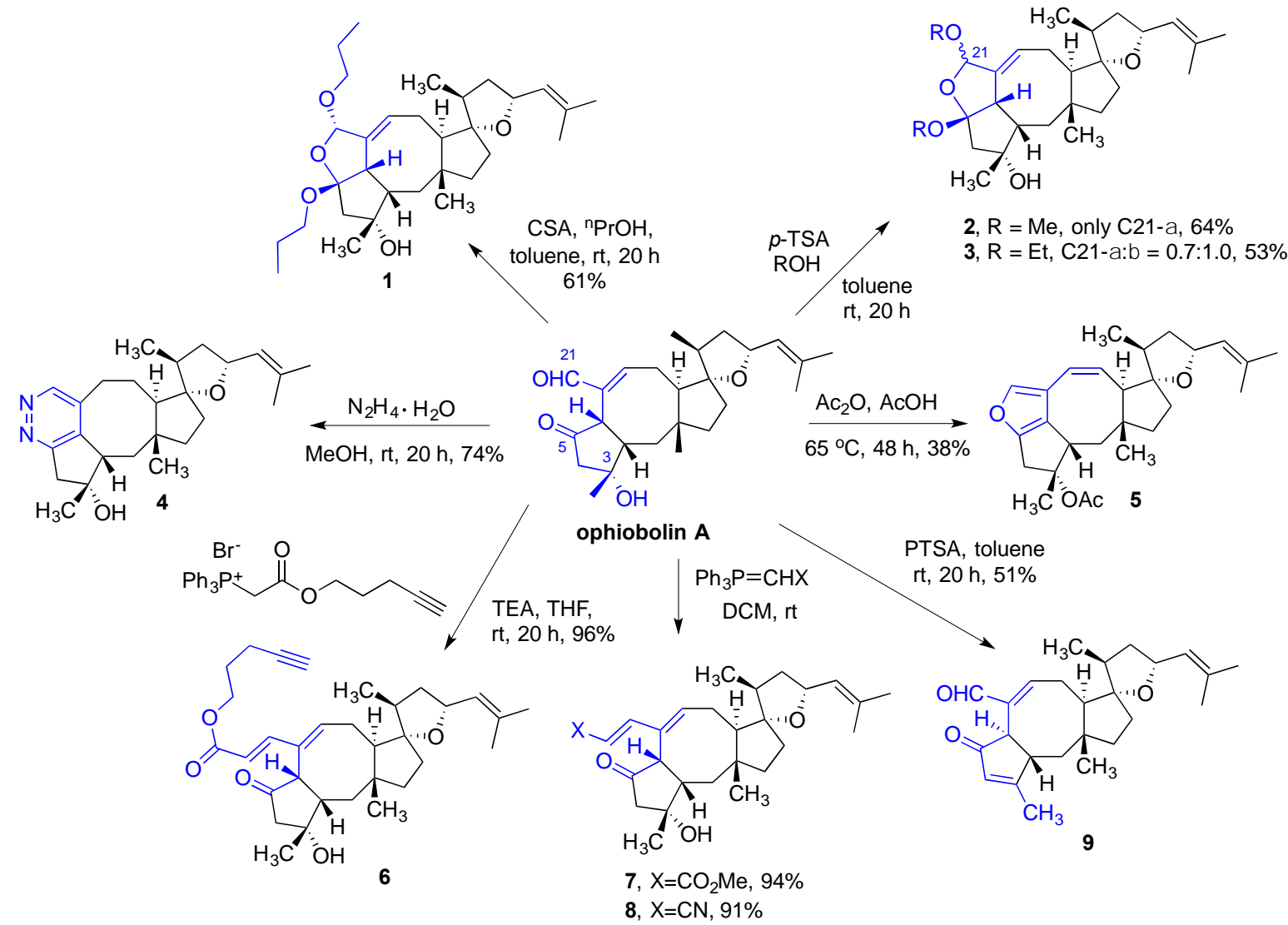

Figure 3. Derivatization involving the $\mathrm{C} 5, \mathrm{C} 21$-dicarbonyl functionality

Next, the reactivity of the C18,C19-alkene was probed (Figure 4). Thus, treatment with $m$-CPBA produced a mixture of $\mathrm{C} 18$-epimeric epoxides $\mathbf{1 0}$. The reaction occurred selectively with the electronrich $\mathrm{C} 18, \mathrm{C} 19$-alkene in the presence of the electron-deficient C7,C8-olefin. Following a dated report $^{30}$ illustrating the possibility of a selective halo-methoxylation of the electron-rich C18,C19alkene, ophiobolin A was subjected to the treatment with bromine in a variety of alcohols as a solvent to obtain C18-bromo-C19-alkoxy derivatives 11-13. In the case of ethoxy and 5-hexynoxy derivatives 11 and 12 only $\mathrm{C} 18-\alpha$ epimers were produced, whereas the major $\mathrm{C} 18-\alpha$ propargyl derivative 13 was accompanied by small amounts of C18- $\beta$ epimer. This stereochemical outcome is consistent with the above-mentioned literature report. ${ }^{30}$ Lastly, the introduction of an alkyne fragment in this manner permitted further functionalization of ophiobolin A using click chemistry, as illustrated with the conversion of $\mathbf{1 3}$ to $\mathbf{1 4 .}$ 


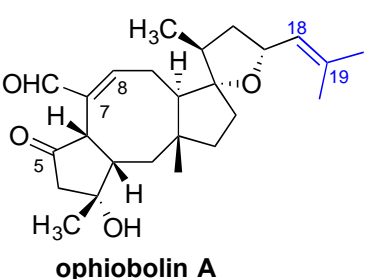

$m$-CPBA, $\mathrm{NaHCO}_{3}$,
DCM, rt, $20 \mathrm{~h}, 70 \%$
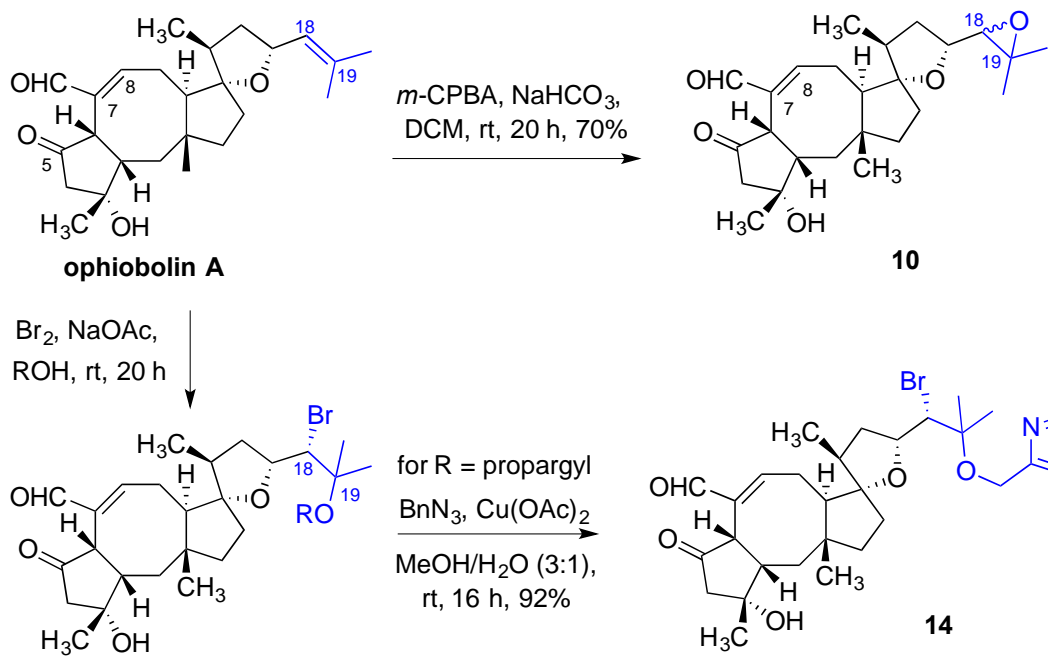

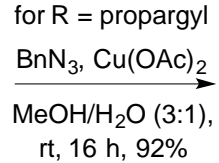

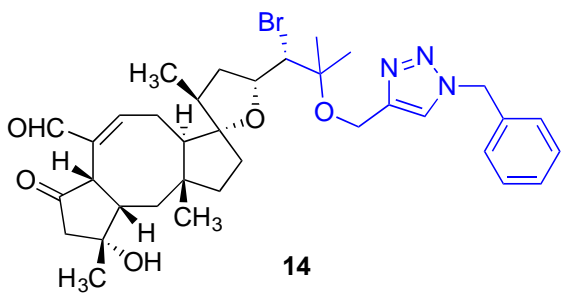

$11, \mathrm{R}=\mathrm{Et}, 50 \%$

12, $\mathrm{R}=5$-hexynyl, $51 \%$

$13, R=$ propargyl, $53 \%$

Figure 4. Derivatization of the C18,C19-olefin

As has been emphasized above, the inspection of the literature concerning the known biological effects associated with the members of the ophiobolin family of sesterterpenoids indicates that the C5,C21-dicarbonyl functionality is critical for activity. ${ }^{25-28}$ Indeed, in the most intriguing discovery of possible biological relevance, ophiobolin A was found to react with primary amines in the presence of small amount of acetic acid forming pyrrole derivatives 15-17 (Figure 5). Although this particular condensation, in which the alkene migrates to the adjacent carbon $(\mathrm{C} 7, \mathrm{C} 8$ to $\mathrm{C} 8, \mathrm{C} 9$ in 15) appears to be unprecedented, in general the Paal-Knorr reaction of primary amines with 1,4-dicarbonyl compounds is a well-studied classical pyrrole synthesis. ${ }^{31}$ The biological significance of this reaction, however, appears to be severely under-appreciated despite the wide occurrence of the 1,4-dicarbonyl functionality in natural products that could potentially react with lysine residues on proteins. The only thoroughly studied example of the biological relevance of the Paal-Knorr reaction is its role in $n$ hexane-induced axonal atrophy in the central nervous system. Specifically, 2,5-hexanedione, a neurotoxic $n$-hexane metabolite, undergoes a selective Paal-Knorr condensation with lysine residues of axonal cytoskeleton proteins, forming 2,5-dimethylpyrrole adducts within specific regions of neurofilaments, as has been demonstrated both in vitro and in vivo systems. ${ }^{32}$ To our knowledge, the only reported example of lysine pyrrolylation with a 1,4-dicarbonyl-containing natural product involves the lysozyme modification with spongian diterpenes, a reaction proposed to be responsible for Golgi-modifying properties of these marine metabolites. ${ }^{33}$

The TLC monitoring of this reaction reveals an immediate formation of a polar intermediate, possibly an imine or dienamine existing in an equilibrium with the starting aldehyde, which is then completely consumed with the formation of the final pyrrole product. Indeed, when this reaction was performed with $\alpha-N$-Ac-lysine in a phosphate buffer at the physiological $\mathrm{pH}$ of 7.4, the pyrrole product 18 was formed in a low $21 \%$ yield. Isolated in slightly larger amounts was imine 19, whose cyclization into the desired pyrrole $\mathbf{1 8}$ is apparently sluggish in the absence of an acid catalyst. This reasoning however supports the idea that in a relatively hydrophobic protein pocket containing an $\mathrm{H}$ bond donating residue, the conditions would be similar to those presented by an organic solvent in the presence of $\mathrm{AcOH}$ leading to a facile pyrrole formation. The structure of pyrrole $\mathbf{1 5}$ was confirmed with ${ }^{1} \mathrm{H}$ and ${ }^{13} \mathrm{C}$ NMR, HRMS and a UV spectrum showing the disappearance of the absorption at 
$236 \mathrm{~nm}$ associated with the parent $\alpha, \beta$-saturated aldehyde functionality and the emergence of the 209 $\mathrm{nm}$ band characteristic of the pyrrole ring. ${ }^{34,35}$

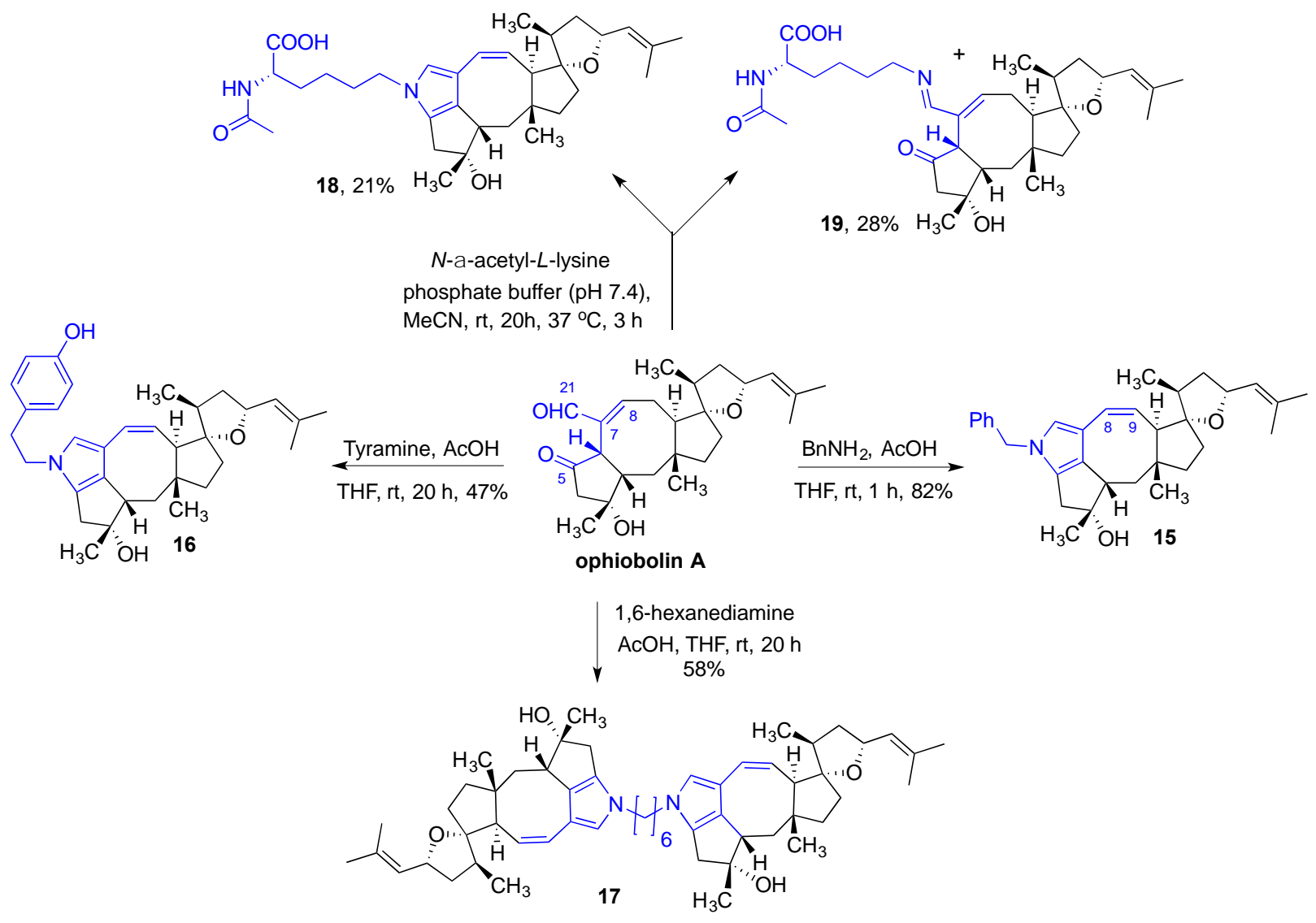

Figure 5. Formation of pyrroles with primary amines

The synthesized compounds were evaluated for in vitro growth inhibition using the MTT colorimetric assay against a panel of five cancer cell lines including apoptosis-resistant human U373 GBM, ${ }^{36}$ human A549 non-small cell lung cancer (NSCLC) ${ }^{37}$ and human SKMEL-28 melanoma, ${ }^{38}$ as well as apoptosis-sensitive human Hs683 anaplastic oligodendroglioma ${ }^{36}$ and human MCF-7 breast cancer. ${ }^{39}$ Analysis of these data shows that derivatives with the eliminated C5,C21-dicarbonyl functionality, such as compounds $\mathbf{4 - 8}$ and 15-18, have significantly reduced potencies as would be expected due to the critical importance of this moiety for anticancer activity. In contrast, compounds incorporating modifications of the $\mathrm{C} 18, \mathrm{C} 19$-alkene, such as 10-14, have retained a significant portion of the antiproliferative potency. Also, of interest is the retention of activity of acetals $\mathbf{1 - 3}$. We have showed that these acetals are hydrolytically labile and regenerate the parent natural product at low $\mathrm{pH}$ values (data not shown). Additionally, these molecules are capable of reacting with primary amines under anhydrous acidic conditions directly forming pyrrole derivatives (data not shown). Thus, it is possible that these derivatives undergo intracellular hydrolysis or react directly with the intracellular target(s) engaging in a covalent complex formation with lysine residue(s). In another instructive example, imine 19 shows single digit micromolar activity possibly due to its slow hydrolysis to the parent natural product, whereas the product of its irreversible cyclization, pyrrole $\mathbf{1 8}$ is completely devoid of activity. Finally, it is noteworthy that in a manner similar to paraptosis inducer ophiobolin 
A, the active derivatives do not discriminate between the cancer cell lines based on the apoptosis sensitivity criterion and display comparable potencies in both cell types, indicating that apoptosis induction is unlikely to be the primary mechanism responsible for antiproliferative activity in this series of compounds.

Table 1. Antiproliferative activities of ophiobolin A synthetic derivatives

\begin{tabular}{|c|c|c|c|c|c|c|c|c|c|c|c|c|c|}
\hline \multirow{3}{*}{ compound } & \multicolumn{6}{|c|}{$\mathrm{GI}_{50}$ in vitro values $(\mu \mathrm{M})^{\mathrm{a}}$} & & \multicolumn{6}{|c|}{$\mathrm{GI}_{50}$ in vitro values $(\mu \mathrm{M})^{\mathrm{a}}$} \\
\hline & \multicolumn{2}{|c|}{ carcinoma } & \multicolumn{2}{|c|}{ glioma } & \multicolumn{2}{|l|}{ melanoma } & \multirow{2}{*}{ compound } & \multicolumn{2}{|c|}{ carcinoma } & \multicolumn{2}{|c|}{ glioma } & \multicolumn{2}{|l|}{ melanoma } \\
\hline & A549 & MCF7 & Hs683 & U373 & SKMEL & mean & & A549 & MCF7 & Hs683 & U373 & SKMEL & mean \\
\hline ophiobolin A & 0.1 & 0.06 & 0.02 & 0.06 & 0.05 & 0.06 & 10 & 0.6 & 0.6 & 0.4 & 0.6 & 0.4 & 0.5 \\
\hline 1 & 0.3 & 0.2 & 0.2 & 0.4 & 0.2 & 0.3 & 11 & 0.9 & 1.2 & 0.9 & 1.2 & 0.6 & 0.9 \\
\hline 2 & 0.3 & 0.4 & 0.4 & 0.4 & 0.3 & 0.4 & 12 & 1 & 1.4 & 0.8 & 2.2 & 0.6 & 1 \\
\hline 3 & 0.3 & 0.2 & 0.2 & 0.4 & 0.1 & 0.2 & 13 & 0.8 & 0.8 & 0.6 & 1.4 & 0.6 & 0.8 \\
\hline 4 & 34 & 27 & 29 & 30 & 29 & 30 & 14 & 1.2 & 1.2 & 0.8 & 3.4 & 1 & 1.4 \\
\hline 5 & 6 & 13 & 11 & 8 & 6 & 9 & 15 & 51 & 40 & 46 & 69 & 58 & 53 \\
\hline 6 & 15 & 12 & 12 & 20 & 23 & 16 & 16 & 35 & 23 & 33 & 54 & 33 & 36 \\
\hline 7 & 59 & 43 & 59 & 86 & 86 & 67 & 17 & 26 & 14 & 25 & 30 & 24 & 24 \\
\hline 8 & 27 & 26 & 22 & 27 & 28 & 26 & 18 & $>100$ & $>100$ & $>100$ & $>100$ & $>100$ & $>100$ \\
\hline 9 & 9 & 10 & 8 & 18 & 8 & 11 & 19 & 3 & 4 & 3 & 4 & 3 & 3 \\
\hline
\end{tabular}

${ }^{\mathrm{a}}$ The cells were cultured in RPMI media supplemented with $10 \%$ heat-inactivated fetal calf, $4 \mathrm{mM}$ glutamine, $100 \mathrm{mg} / \mathrm{mL}$ gentamicin and penicillin, streptomycin $(200 \mathrm{U} / \mathrm{mL}$ and $200 \mathrm{mg} / \mathrm{mL})$. The overall growth level of each cell line was determined using the colorimetric MTT (3-[4,5-dimethyl thiazol-2-yl-diphenyl tetrazolium bromide) assay. Each experimental condition was performed in six replicates with ophiobolin A used as internal control and the data have been normalized accordingly to ensure appropriate comparison.

In conclusion, the first synthetically generated structure-activity relationship support the critical role played by the C5,C21-dicarbonyl functionality in the antiproliferative effects of ophiobolin A and its analogues. In conjunction with the initial promising in vivo effects of this natural product in a mouse GBM xenograft model, these results should provide further impetus and guidance for the pursuit of ophiobolin A as an anti-GBM agent with an innovative mode of action. In addition, the unique reaction of ophiobolin A with primary amines suggests the possibility of pyrrolylation of lysine residues on its intracellular target protein(s). This finding should instigate further research efforts to study the biological significance of the Paal-Knorr pyrrole formation reaction and gain valuable insight into protein modification with natural products via this underexplored chemical mechanism. Because the 1,4 dicarbonyl motif as well as its masked (e.g., bis-furanose) variants is a common structural feature in natural products, it could be hypothesized that many of these molecules covalently modify their protein targets through pyrrole formation with active site lysine residues. 


\section{Acknowledgments}

This project was supported by the grant from the National Cancer Institute (CA186046-01A1), Welch Foundation (AI-0045), National Science Foundation (NSF award 0946998) and the Belgian Tumor Support Group (BBTS; Belgium). RK is a director of research with the Fonds National de la Recherche Scientifique (FRS-FNRS; Belgium). We thank Thierry Gras for technical assistance.

\section{References and Notes}

1. Agnihotri, S.; Burrell, K. E.; Wolf, A.; Jalali, S.; Hawkins, C.; Rutka, J. T.; Zadeh, G. Arch. Immunol. Ther. Exp. 2013, 61, 25-41.

2. Stupp, R.; Hottinger, A. F.; van den Bent, M. J.; Dietrich, P. Y.; Brandes, A. A. Ann. Oncol. 2008, 19 (Suppl. 7), 209-216.

3. Stupp, R.; Hegi, M. E.; Mason, W. P.; van den Bent, M. J.; Taphoorn, M. J. B.; Janzer, R. C.; Ludwin, S. K.; Allgeier, A.; Fisher, B.; Belanger, K.; Hau, P.; Brandes, A. A.; Gijtenbeek, J.; Marosi, C.; Vecht, C. J.; Mokhtari, K.; Wesseling, P.; Villa, S.; Eisenhauer, E.; Gorlia, T.; Weller, M.; Lacombe, D.; Cairncross, J. G.; Mirimanoff, R.-O.; on behalf of the European Organisation for Research and Treatment of Cancer Brain Tumour and Radiation Oncology Groups and the National Cancer Institute of Canada Clinical Trials Group. Lancet Oncol. 2009, 10, 459-466.

4. Weller, M.; Stupp, R.; Reifenberger, G.; Brandes, A. A.; van den Bent, M. J.; Wick, W.; Hegi, M. E. Nat. Rev. Neurol. 2010, 6, 39-51.

5. Fulda, S.; Wick, W.; Weller, M.; Debatin, K. M. Nat. Med. 2002, 8, 808-815.

6. Tanaka, S.; Louis, D. N.; Curry, W. T.; Batchelor, T. T.; Dietrich, J. Nat. Rev. Clin. Oncol. 2013, 10, 14-26.

7. Gilbert, M. R.; Dignam, J.; Won, M.; Blumenthal, D. T.; Vogelbaum, M. A.; Aldape, K. D.; Colman, H.; Chakravarti, A.; Jeraj, R.; Armstrong, T. S.; Wefel, J. S.; Brown, P. D.; Jaeckle, K. A.; Schiff, D.; Atkins, J. N.; Brachman, D.; Werner-Wasik, M.; Komaki, R.; Sulman, E. P.; Mehta, M. P. J. Clin. Oncol. 2013, 31 (suppl; abstr 1).

8. Adamson, C.; Kanu, O. O.; Mehta, A. I.; Di, C.; Lin, N.; Mattox, A. K. Expert Opin. Invest. Drugs. 2009, 18, 1061-1083.

9. Krakstad, C.; Chekenya, M. Mol. Cancer 2010, 9, 135.

10. Eisele, G.; Weller, M. Cancer Lett. 2013, 332, 335-345.

11. Kornienko, A.; Mathieu, V.; Rastogi, S.; Lefranc, F.; Kiss, R. J. Med. Chem. 2013, 56, 48234839.

12. Bury, M.; Girault, A.; Mégalizzi, V.; Spiegl-Kreinecker, S.; Mathieu, V.; Berger, W.; Evidente, A.: Kornienko, A.; Gailly, P.; Vandier, C.; Kiss, R. Cell Death Dis. 2013, 4, e569.

13. Dasari, R.; Banuls, L. M. Y.; Masi, M.; Pelly, S. C.; Mathieu, V.; Green, I. R.; van Otterlo, W. A. L.; Evidente, A.; Kiss, R.; Kornienko, A. Bioorg. Med. Chem. Lett. 2014, 24, 923-927.

14. Van Goietsenoven, G.; Mathieu, V.; Lefranc, F.; Kornienko, A.; Evidente, A.; Kiss, R. Med. Res. Rev. 2013, 33, 439-455.

15. Luchetti, G.; Johnston, R.; Mathieu, V.; Lefranc, F.; Hayden, K.; Andolfi, A.; Lamoral-Theys, D.; Reisenauer, M. R.; Champion, C.; Pelly, S. C.; van Otterlo, W. A. L.; Magedov, I. V.; Kiss, R.; Evidente, A.; Rogelj, S.; Kornienko, A. ChemMedChem, 2012, 7, 815-822.

16. Evdokimov, N.; Lamoral-Theys, D.; Mathieu, V.; Andolfi, A.; Pelly, S.; van Otterlo, W.; Magedov, I.; Kiss, R.; Evidente, A.; Kornienko, A. Bioorg. Med. Chem. 2011, 19, 72527261. 
17. Dasari, R.; Kornienko, A. Chem. Heterocycl. Compd. 2014, 160-165.

18. Van Goietsenoven, G.; Hutton, J.; Becker, J. -P.; Lallemand, B.; Robert, F.; Lefranc, F.; Pirker, C.; Vandenbussche, G.; Van Antwerpen, P.; Evidente, A.; Berger, W.; Prévost, M.; Pelletier, J.; Kiss, R.; Kinzy, T. G.; Kornienko, A.; Mathieu, V. FASEB J. 2010, 24, 45754584.

19. Scott, R.; Karki, M.; Reisenauer, M. R.; Rodrigues, R.; Dasari, R.; Smith, W. R.; Pelly, S. C.; van Otterlo, W. A. L.; Shuster, C. B.; Rogelj, S.; Magedov, I. V.; Frolova, L. V.; Kornienko, A. ChemMedChem 2014, 9, 1428-1435.

20. Lamoral-Theys, D.; Pottier, L.; Kerff, F.; Dufrasne, F.; Proutiere, F.; Wauthoz, N.; Neven, P.; Ingrassia, L.; Van Antwerpen, P.; Lefranc, F.; Gelbcke, M.; Pirotte, B.; Kraus, J. L.; Neve, J.; Kornienko, A.; Kiss, R.; Dubois, J. Bioorg. Med. Chem. 2010, 18, 3823-3833.

21. Sperandio, S.; de Belleand, I.; Bredesen, D. E. Proc. Nat. Acad. Sci. 2000, 97, 14376-14381.

22. Sperandio, S.; Poksay, K.; de Belle, I.; Lafuente, M. J.; Liu, B.; Nasir, J.; Bredesen, D. E. Cell Death Diff. 2004, 11, 1066-1075.

23. Pais, V.; Danaila, L.; Pais, E. Ultrastruct. Pathol. 2013, 37, 110-120.

24. Bury, M.; Novo-Uzal, E.; Andolfi, A.; Cimini, S.; Wauthoz, N.; Heffeter, P.; Lallemand, B.; Avolio, F.; Delporte, C.; Cimmino, A.; Dubois, J.; Van Antwerpen, P.; Zonno, M. C.; Vurro, M.; Poumay, Y.; Berger, W.; Evidente, A.; De Gara, L.; Kiss, R.; Locato, V. Int. J. Oncol. 2013, 43, 575-585.

25. Au, T. K.; Chick, W. S. H.; Leung, P. C. Life Sci. 2000, 67, 733-742.

26. Ahn, J. -W.; Lee, M. K.; Choi, S. U.; Lee, C. O.; Kim, B. -S. J. Microbiol. Biotech. 1998, 8, 406-408.

27. Wei, H.; Itoh, T.; Kinoshita, M.; Nakai, Y.; Kurotaki, M.; Kobayashi, M. Tetrahedron 2004, 60, 6015-6019.

28. Liu, H. B.; Edrada-Ebel, R.; Ebel, R.; Wang, Y.; Schulz, B.; Draeger, S.; Müller, W, E. G.; Wray, V.; Lin, W. H.; Proksch, P. Helv. Chim. Acta 2011, 94, 623-631.

29. For the purposes of this investigation, ophiobolin A was isolated from Drechslera gigantea as reported previously (Ref. 24). The purity of $>95 \%$ was determined by RP-HPLC-UV.

30. Nozoe, S.; Morisaki, M.; Tsuda, K.; Iitaka, Y.; Takahashi, N.; Tamura, S.; Ishibashi, K.; Shirasaka, M. J. Am. Chem. Soc. 1965, 87, 4968-4970.

31. Amarnath, V.; Anthony, D. C.; Amarnath, K.; Valentine, W. M.; Wetterau, L. A.; Graham, D. G. J. Org. Chem. 1991, 56, 6924-6931.

32. Zhang, L.; Gavin, T.; DeCaprio, A. P.; LoPachin, R. M. Toxicol. Sci. 2010, 117, 180-189.

33. Schneimann, M. J.; Beaudry, C. M.; Genung, N. E.; Canham, S. M.; Untiedt, N. L.; Karanikolas, B. D. W.; Sutterlin, C.; Overman, L. E. J. Am. Chem. Soc. 2011, 133, 1749417503.

34. Characterization data for pyrrole 15: ${ }^{1} \mathrm{H}$ NMR (400 MHz, $\left.\mathrm{C}_{6} \mathrm{D}_{6}\right) \delta 7.06-6.86(\mathrm{~m}, 5 \mathrm{H}), 6.75$ (ddd, $J=10.8,1.2,0.4 \mathrm{~Hz}, 1 \mathrm{H}), 6.36(\mathrm{~s}, 1 \mathrm{H}), 5.55$ (dd, $J=10.8,9.2 \mathrm{~Hz}, 1 \mathrm{H}), 5.31-5.27$ (m, $1 \mathrm{H}), 4.73-4.64(\mathrm{~m}, 1 \mathrm{H}), 4.39,4.34\left(\mathrm{ABq}, J_{A B}=15.6 \mathrm{~Hz}, 2 \mathrm{H}\right), 3.18(\mathrm{~s}, 1 \mathrm{H}), 2.76(\mathrm{dd}, J=$ 13.0, $5.0 \mathrm{~Hz}, 1 \mathrm{H}), 2.48(\mathrm{~d}, J=15.1 \mathrm{~Hz}, 1 \mathrm{H}), 2.34(\mathrm{~d}, J=15.1 \mathrm{~Hz}, 1 \mathrm{H}), 2.21-2.16(\mathrm{~m}, 1 \mathrm{H})$, $1.99-1.75(\mathrm{~m}, 2 \mathrm{H}), 1.70-1.58(\mathrm{~m}, 5 \mathrm{H}), 1.54(\mathrm{~d}, J=1.3 \mathrm{~Hz}, 3 \mathrm{H}), 1.48(\mathrm{~d}, J=1.3 \mathrm{~Hz}, 3 \mathrm{H})$, $1.44-1.38(\mathrm{~m}, 2 \mathrm{H}), 1.26(\mathrm{~s}, 3 \mathrm{H}), 1.01(\mathrm{~d}, J=6.8 \mathrm{~Hz}, 3 \mathrm{H}), 0.95(\mathrm{~s}, 3 \mathrm{H}) ;{ }^{13} \mathrm{C} \mathrm{NMR}(100 \mathrm{MHz}$, $\left.\mathrm{C}_{6} \mathrm{D}_{6}\right) \delta 138.2,136.5,134.6,134.1,132.8,129.0,128.7,127.3,126.5,124.9,122.8,118.7$, 96.8, 84.7, 72.1, 58.4, 51.5, 49.4, 43.7, 42.1, 41.9, 41.4, 36.6, 30.8, 30.0, 29.9, 26.7, 25.5, 23.0, 17.1; HRMS (ESI) calcd for $\mathrm{C}_{32} \mathrm{H}_{42} \mathrm{NO}_{2}(\mathrm{M}+\mathrm{H}) 472.3216$, found 472.3213 . 
35. Jones R. A. The chemistry of heterocyclic compounds, pyrroles; Ed.; Wiley: 2009; Vol. 48, Part 1, p 48.

36. Lefranc, F.; Nuzzo, G.; Hamdy, N. A.; Fakhr, I.; Moreno Y Banuls, L.; Van Goietsenoven, G.; Villani, G.; Mathieu, V.; van Soest, R.; Kiss, R.; Ciavatta, M. L. J. Nat. Prod. 2013, 76, 1541-1547.

37. Mathieum, A.; Remmelink, M.; D’Haene, N.; Penant, S.; Gaussin, J. F.; Van Ginckel, R.; Darro, F.; Kiss, R.; Salmon, I. Cancer 2004, 101, 1908-1918.

38. Mathieu, V.; Pirker, C.; Martin de Lasalle, E.; Vernier, M.; Mijatovic, T.; De Neve, N.; Gaussin, J. F.; Dehoux, M.; Lefranc, F.; Berger, W.; Kiss, R. J. Cell. Mol. Med. 2009, 13, 3960-3972.

39. Frolova, L. V.; Magedov, I. V.; Romero, A. E.; Karki, M.; Otero, I.; Hayden, K.; Evdokimov, N. M.; Banuls, L. M. Y.; Rastogi, S. K.; Smith, W. R.; Lu, S. L.; Kiss, R.; Shuster, C. B.; Hamel, E.; Betancourt, T.; Rogelj, S.; Kornienko, A. J. Med. Chem. 2013, 56, 6886-6900. 